\title{
Valor, estranhamento e lutas de classes: a necessidade da crítica ontológica
}

\author{
Value, alienation and class struggles: \\ the need for ontological criticism
}

Thiago Dutra Hollanda de Rezende*

\begin{abstract}
Resumo - O presente trabalho parte dos limites da crítica às formas políticas capitalistas de resolução das mazelas sociais, deixando em segundo plano a crítica que advinda da gênese, do caráter e da necessidade das relações sociais de produção concretas dadas em cada particularidade. Em seguida, aponta elementos que indicam a necessidade de se pensar uma crítica à sociedade capitalista que enfatize o estranhamento das relações sociais a partir da esfera de produção e reprodução do valor, sendo essa, necessariamente, uma crítica ontológica, a qual vai à raiz das determinações das lutas de classes no capitalismo. Por meio da análise de realidade que essa perspectiva propicia, é possível partir de cada particularidade concreta. Desse modo, pode-se compreender as específicas formas políticas e, assim, avaliar a potencial instrumentação dessas pelos trabaIhadores, em uma tática que comporte uma simultaneidade de ações articuladas para a sua emancipação, superando-se o politicismo e o indiferentismo político.
\end{abstract}

Palavras-chave: formas políticas; valor; crítica ontológica; estranhamento; lutas de classes.

\begin{abstract}
This work has as its starting point the limits of the criticism restrained to capitalist political forms of solving social problems, leaving in the background criticism coming from the genesis, character and needs of the concrete social relations of production that each case demands. Then, it indicates elements that reflect the need to develop a criticism of capitalist society that emphasizes the alienation of social relations from the sphere of production and reproduction of value. This is necessarily an ontological criticism, which seeks the root of the determinations of class struggles under capitalism. Through the analysis of reality this perspective provides, it is possible to start from each concrete particularity to understand the specific political forms and thus evaluate the possible instrumentation of them by workers in a tactic that includes simultaneous joint actions for their emancipation, surpassing politicism and political indifference.

Keywords: political forms; value; ontological criticism; alienation; class struggle.
\end{abstract}

\footnotetext{
* Mestrando em Política Social pela Universidade de Brasília e servidor público do Ministério Público da União. Correspondência: SAS Quadra 5, Bloco E, Lote 8, sala 105. Asa Sul, Brasília-DF. CEP 70070-911. Email: $<$ thiagodhr@gmail.com>
} 


\section{Introdução}

O assim chamado mundo capitalista globalizado não cumpriu sua promessa. Ao invés de o capitalismo resolver as iniquidades e mazelas globais por meio da sua expansão, livre de promessas de projetos societários alternativos, assistimos à (re)produção de um mundo em que fica cada vez mais difícil varrer para debaixo do tapete a miserabilidade, a barbárie, a violência etc. O Papa Francisco lançou uma encíclica abordando a desigualdade global. Na Laudato Si', o pontífice enfoca a degradação ambiental, tendo em vista "[...] proteger a nossa casa comum [...]" (IGREJA CATÓLICA, 2015 p. 12) das "[...] consequências danosas dos estilos de vida, produção e consumo[...]" (IGREJA CATÓLICA, 2015, p. 127). Francisco enfoca as questões da desigualdade e da pobreza como urgentes, considera os mais pobres como os mais afetados pela deterioração ambiental e propõe aos países ricos que limitem o consumo de energias não renováveis, exigindo padrões globais de regulação da poluição, além de pedir por mais solidariedade. Sugere aos países pobres que "[...] as prioridades devem ser a erradicação da miséria e o desenvolvimento social dos seus habitantes" (IGREJA CATÓLICA, 2015, p. 172-173).

Apesar de sua atuação predatória e das prescrições dadas tradicionalmente (HARVEY, 2003; BORÓN, 2009), o FMI (2015) publicou um estudo no qual sugere a necessidade de uma reversão nas taxas regressivas de impostos e, com base em ampla evidência empírica, rejeita a teoria do "trickle-down". Além disso, conclui que melhor acesso à educação, meIhores políticas de saúde e políticas sociais redistributivas ajudam a aumentar a renda dos mais pobres e da classe média, independente do nível de desenvolvimento econômico do país. Constata, por fim, que, a partir de certo nível, a desigualdade se torna barreira ao crescimento econômico.

Este estudo, por referências diretas e metodologia, é influenciado pelo francês Thomas Piketty (2014). O autor observa o crescimento da desigualdade no mundo a partir dos anos 1970 e destaca o papel das instituições sociais na manutenção da desigualdade em níveis adequados ao bom funcionamento da democracia e à promoção da justiça social. Paul Krugman (2014) atesta o diagnóstico de Piketty, definindo-o como magistral, e diz que nunca mais falaremos sobre riqueza e desigualdade como antes. Há alguns anos ele também tem criticado a maneira como a União Europeia e os Estados Unidos vêm manejando a crise, e tem defendido uma alternativa neokeynesiana às receitas de austeridade (KRUGMAN, 2012).

Por outro lado, Chesnais (2009) considera que o regime de acumulação do capital mundializado é inviável por conta da desigualdade e da injustiça ele que gera. Além disso, também pelo fato de que os mecanismos financeiros que puderam permitir ao capital ignorar as condições de produção e realização do valor estão se exaurindo. Harvey (2003) afirma que o brilho do método dialético de Marx está em demonstrar que 


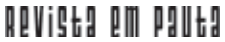

\} VALOR, ESTRANHAMENTO E LUTAS DE CLASSES - REZENDE, T. D. H. \}

DOI: $10.12957 /$ REP.2016.27840

a liberalização do mercado produzirá níveis cada vez maiores de desigualdade social. Já Pereira (2013, p. 273) defende que as lutas proletárias "[...] devem inscrever-se no bojo de uma luta maior, contínua, pela busca do bem-estar total, o único humanamente emancipador". A "proteção social possível" deve "[...] contribuir para a conscientização da classe oprimida beneficiária, emancipando-a gradualmente" (PEREIRA, 2013, p. 274).

Com diferentes justificativas, há a retomada da defesa do papel do Estado enquanto regulador e indutor do desenvolvimento e/ou protetor social no debate público e teórico. Assim, temos basicamente duas críticas às mazelas sociais e às desigualdades originadas no capitalismo: uma que busca sua harmonização (papa, democratas, Piketty, neokeynesianos etc.), e outra que busca a sua superação (marxistas). O que há em comum é a ênfase na desigualdade, na distribuição da riqueza social como fator de desarmonia ou de barbárie. Entretanto, Duayer e Medeiros (2008, p. 157) argumentam que, dessa maneira, temos uma crítica marxista que:

[...] alimenta um debate com a ciência econômica burguesa (o pleonasmo usado aqui a título de ênfase) justamente no campo que a favorece, vale dizer, em um terreno em que não se discute a natureza histórica da sociedade do capital, suas contradições, sua desumanidade, sua excentricidade em relação aos sujeitos, mas simplesmente a repartição da riqueza.

Para os autores, há a ausência da ênfase na crítica ontológica da sociedade capitalista, do papel do estranhamento da produção em relação aos sujeitos sociais, que são os sujeitos cuja prática e teoria podem possibilitar a transformação e a superação efetiva do modo de produção capitalista. Nesse sentido, tendo em vista a retomada, por diferentes prismas, da necessidade da intervenção do Estado na questão social e nas diferentes formas de mazelas sociais contemporâneas, mais uma vez se coloca a questão sobre qual deve ser a posição dos trabalhadores diante das reformas sociais e de atuação por meio do aparelho estatal.

As reformas sociais são um caminho gradual para além do capital? Ou o Estado é apenas forma de dominação e não deve fazer parte de uma estratégia emancipatória? Ou, ainda, a ação dos trabalhadores deve comportar uma simultaneidade de ações em todas as esferas abertas à sua atuação? Tendo em vista essas questões, no presente texto analisaremos, em primeiro lugar, os limites da crítica que se prende às formas políticas capitalistas de resolução das mazelas sociais, deixando em segundo plano a crítica que parte da gênese, do caráter e da necessidade das relações sociais de produção concretas dadas em cada particularidade. Em seguida, apontaremos elementos que indicam a necessidade de se pensar uma crítica à sociedade capitalista que enfatize o estranhamento das relações sociais, sendo essa, necessariamente, uma crítica ontológica que vai à raiz das determinações das lutas de classes no capitalismo. A partir da análise de realidade 
que essa perspectiva propicia, é possível partir de cada particularidade concreta na crítica das formas políticas e na instrumentação dessas pelos trabalhadores, numa tática que comporte uma simultaneidade de ações articuladas para a sua emancipação.

\section{Determinações das formas políticas, politicismo e indiferentismo político}

Ao discutir e explicar o Estado de Bem-Estar, Gough (1978) o define como ambíguo, pois, ao mesmo tempo em que é meio de repressão e reprodução capitalista, ele também mitiga a dureza da economia de mercado e forma um salário social que deve ser defendido pelos trabalhadores. Ou seja, o Estado de Bem-Estar promove o controle social sobre as forças de mercado e melhora a vida dos indivíduos, inclusive suas capacidades individuais, mas tende a controlá-los e adaptá-los à economia capitalista. Propondo-se a refutar o enfoque marxista que exagera o caráter reprodutor das relações capitalistas, o autor argumenta que, ao atender à demanda dos trabalhadores na forma de salários mais altos ou ajudas sociais, o Estado de Bem-Estar engloba uma atitude racional que se opõe ao mercado. Assim, esse Estado contradiz os requisitos da acumulação capitalista na forma de garantia de direitos e satisfação de necessidades.

Para Navarro (1998), o pensamento neoliberal e sua institucionalização no desmonte dos estados de bem-estar trouxeram consequências sociais deletérias, especialmente na ampliação das desigualdades e do desemprego. Após expor as falácias e os resultados da guinada neoliberal a partir da década de 1970, o autor propõe a retomada do Estado de BemEstar Social como parte da solução desses problemas, aumentando a demanda interna agregada pelo investimento social e redução das desigualdades sociais. Um "[...] investimento considerável em capital humano e infraestrutura física e investigação e uma regulação dos mercados financeiros, penalizando sua especulação, junto a uma diminuição das flutuações monetárias" (NAVARRO, 1998, p. 107).

Pereira (2013) defende que Marx buscava um bem-estar social total. Segundo a autora, há uma "[...] afinidade conceitual das categorias autonomia, associada aos direitos sociais e à igualdade substantiva [...] com a concepção de emancipação humana, adotada por Marx" (PEREIRA, 2013, p. 76 - grifos no original). Assim, é preciso que se busquem "[...] os direitos sociais, que devem ser concretizados por políticas públicas, tendo como premissa a justiça social em associação direta com a concepção de igualdade substantiva" (PEREIRA, 2013, p. 58).

Estratégia semelhante foi definida por Coutinho (2000, p. 47) como "reformismo revolucionário", que se caracteriza por "[...] um reformismo que tem como objetivo explícito aprofundar a democracia e superar o 


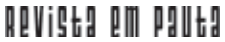

\} VALOR, ESTRANHAMENTO E LUTAS DE CLASSES - REZENDE, T. D. H. \}

DOI: $10.12957 /$ REP.2016.27840

capitalismo [...]". Para o autor, trata-se precisamente da radicalização da política de reformas:

[...] o objetivo deveria ser a obtenção do consenso político necessário para reformas de novo tipo, efetivamente estruturais, que tenha como objetivo a progressiva construção de uma nova lógica de acumulação e de investimento, não mais centrada na busca do lucro e na satisfação do consumo puramente privado, mas no crescimento do bemestar social e dos consumos coletivos. Isso demanda modificações no estatuto da propriedade, [...] de fazer com que o setor público com controle público - se torne o setor hegemônico, o que implica conceber também a propriedade como direito social (COUTINHO, 2000, p. 46 - grifos nossos).

Além disso, Coutinho (2000, p. 47) defende que "[...] a luta pela democracia e a luta pelo socialismo são duas faces solitárias da mesma moeda", ou, na "[...] feliz expressão de um dos últimos documentos do Partido Comunista Italiano, 'a democracia não é um caminho para o socialismo, mas sim o caminho do socialismo'” (COUTINHO, 2000, p. 24 grifos no original).

Podemos inferir que, para Coutinho (2000), a consolidação das instituições democráticas, bem como as reformas e os direitos sociais, seriam o caminho necessário para o socialismo. Ou seja, haveria uma resposta positiva à nossa primeira pergunta colocada na introdução, qual seja, se as reformas sociais seriam um caminho gradual para além do capital. A atenção à contingência e às determinações e diferenças específicas de tempo, espaço e condições sociais das lutas dos trabalhadores, no entanto, podem levar a outra apreensão, conforme Marx (2011a, p. 216-217 - grifos nossos):

As uniões de trabalhadores não podem ser absolutamente idênticas, em seus mínimos detalhes, em Newcastle e em Barcelona, em Londres e em Berlim. Na Inglaterra, por exemplo, o caminho para a demonstração de poder político está aberto à classe trabalhadora. A insurreição seria uma loucura, enquanto a agitação pacífica serviria aos fins de modo mais rápido e certo. Na França, uma centena de leis de repressão e um antagonismo mortal entre as classes parecem necessitar de uma solução violenta da guerra social. A escolha dessa solução é um assunto das classes trabalhadoras daquele país.

Assim, na análise marxiana, não há um instrumento ou método de luta absoluto da classe trabalhadora. A avaliação das condições objetivas e subjetivas é fundamental para a construção e constituição dos meios que buscam a transformação radical da sociedade, o que coloca em questão a tese do reformismo revolucionário. Essa diferença se dá porque, em uma análise materialista da realidade, não há espaço para uma teorização autônoma do político, ou, ainda, uma abordagem do político descolada de sua 


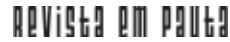

\} VALOR, ESTRANHAMENTO E LUTAS DE CLASSES - REZENDE, T. D. H. \}

DOI: $10.12957 /$ REP. 2016.27840

base material (PAÇO-CUNHA, 2015). Essa extrapolação nos leva ao politicismo.

Segundo Chasin (1982, p. 7), "politicizar é tomar e compreender a totalidade do real exclusivamente pela sua dimensão política e, ao limite mais pobre, apenas de seu lado político-institucional". A tese do reformismo revolucionário pende para o politicismo na medida em que toma determinadas formas políticas descoladas de suas determinações sociais e históricas específicas. Direitos sociais, democracia, justiça social e outros entes políticos assumem características e formas diversas, sendo sua possibilidade e condicionalidade determinadas por cada particularidade nacional, de modo que postulação do autor definindo como "o caminho para o socialismo" só é possível quando se teorizam autonomamente as formas políticas.

Para evitar os riscos da análise politicista e, mais importante, da ação político-social dela derivada, é necessário ancorar o movimento da forma política em seus pressupostos materiais, quais sejam, econômicos, sociais, históricos e locais. Assim, a análise de realidade permite desvelar concretamente as condições objetivas para a ação organizada dos trabaIhadores.

De forma alguma advogamos que os meios para atingir esses objetivos sejam idênticos em todo lugar. Nós sabemos que instituições, costumes e tradições devem ser levados em conta; e nós não negamos a existência de países como os Estados Unidos, a Inglaterra, e se eu conhecesse melhor suas instituições eu poderia somar a Holanda, onde os trabalhadores podem atingir seus objetivos por meios pacíficos. (MARX, 1988a, p. 255 - grifos nossos).

É necessário considerar o papel das instituições, costumes e tradições para pensar as formas possíveis de conformação das lutas das trabalhadoras e dos trabalhadores. Os meios políticos não existem separados das condições objetivas e subjetivas de utilização. A existência de um fim comum não garante e nem necessita de um meio universal, ou, ainda, uma forma política universal é objetivamente inviável e nem é desejável enquanto instrumento emancipatório. Desse modo, a consideração da reforma social e da política social - elemento estatal manejável -, enquanto instrumento emancipatório, deve levar em conta as especificidades locais, institucionais, tradicionais, culturais e históricas onde será concretizada. Em suma, é necessária a análise da particularidade.

A título de exemplo, em uma carta à revolucionária Vera Zasulich, de 1881, Marx (2013b, p. 89-90 - grifos nossos) afirmou que a comuna rural russa poderia se livrar gradualmente de suas características primitivas e "[...] se desenvolver diretamente como elemento da produção coletiva em escala nacional. É justamente graças à contemporaneidade da produção capitalista que ela pode se apropriar de todas as conquistas positivas e isto sem passar por suas vicissitudes desagradáveis". Entretanto, Marx (2013a, 


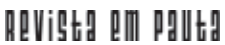

\} VALOR, ESTRANHAMENTO E LUTAS DE CLASSES - REZENDE, T. D. H. \}

DOI: $10.12957 /$ REP.2016.27840

p. 69) alertava que "[...] jamais se chegará a isso tendo como chave-mestra uma teoria histórico-filosófica geral, cuja virtude suprema consiste em ser supra-histórica".

Não é possível existir um modelo de política social universal, da mesma forma como inexiste uma forma política universal. De acordo com Marx (2010), a consideração dos atos políticos é sempre levada em conta como uso de um meio, sendo esse o limite das ações políticas e da administração estatal no modo de produção capitalista. As condições de agir são determinadas pelas condições sociais específicas, das quais se demanda a intervenção estatal, e não pelo caráter da forma política tomada de forma autônoma. Daí que:

O princípio da política é a vontade. Quanto mais unilateral, ou seja, quando mais bem-acabado for o entendimento político, tanto mais ele acredita na onipotência da vontade, tanto mais cego ele é para as limitações naturais e intelectuais da vontade, tornando-se, portanto, tanto menos capaz de desvendar a fonte das mazelas sociais. (MARX, 2010, p. 41 - grifos no original).

Ou seja, é necessário ir além das formas políticas e desvelar a fonte das mazelas sociais nas relações sociais que necessitam das diferentes formas políticas. Estas formas são determinadas pelas "[...] necessidades práticas e o estágio da luta de classes que são postos pelo movimento interno e contraditório da sociabilidade do capital" (PAÇO-CUNHA, 2015, p. 17). As diferentes formas de atuação e reação do Estado diante das lutas de classes, sejam medidas coercitivas e/ou não coercitivas, levam à conclusão de que:

O modo de atuação sincrético do estado é [...] um produto da lógica interna do próprio capitalismo. Não significa que por meio dessas medidas estejam postos no horizonte a superação desse particular modo de produção, nem que tais medidas não possam regredir muitíssimo, indo na direção contrária aos interesses dos trabalhadores, mas se trata de indicar a forma do movimento interno dessa sociabilidade determinada, efeitos de suas contradições imanentes. (PAÇOCUNHA, 2015, p. 17).

O sincretismo da ação estatal, que reprime e conforma ao mesmo tempo em que garante direitos e conquistas sociais, nos remete à crítica do que Marx chamou de indiferentismo político em uma publicação de 1873. Nesse texto, Marx (1988b, p. 392) ironiza as posições que diminuíam a importância das lutas políticas e econômicas em prol dos supostos "[...] eternos princípios da emancipação da classe trabalhadora!" Com sarcasmo, Marx critica as posições, especialmente proudhonistas, que negavam a importância das concessões dentro do Estado burguês, como a limitação da jornada de trabalho, o financiamento estatal da educação básica, o repúdio 
aos meios pacíficos de lutas etc., por serem contrárias aos "princípios eternos". Após simular como seria se os expoentes dessas posições expressassem claramente o que queriam dizer, arremata Marx (1988b, p. 393394):

Não pode ser negado que se os apóstolos do indiferentismo político se expressassem com tanta clareza, a classe trabalhadora faria pouco caso deles e se ressentiria por ser insultada por esses deslocados senhores doutrinados pela burguesia, que são tão estúpidos e ingênuos a ponto de negar a classe trabalhadora qualquer meio real de luta.

Marx (1988b) então explica que os limites das análises dos socialistas utópicos, como Owen, Fourier e Saint-Simon, eram condicionados socialmente. Não havia um movimento da classe trabalhadora organizado politicamente que colocasse novas possibilidades de ação social e política. Por essa razão, esses autores só podiam sonhar com ideais de uma sociedade modelo, não podendo avançar em sua análise por conta dos limites postos pela realidade de sua época. Assim, Marx (1988b) evidencia a impossibilidade de qualquer preponderância de um princípio universal sobre as possibilidades concretas para a ação emancipatória dos trabalhadores. O indiferentismo político tenderia apenas a deixar os trabalhadores desarmados diante da ação política organizada da burguesia, a qual não teria oposição. Marx (1988b) destaca a importância das concessões conquistadas para possibilitar condições objetivas e subjetivas de organização e formação política dos trabalhadores. Tratava-se de não rejeitar os meios reais de luta.

As reformas sociais convivem com o sempre presente risco de regressos, conforme a história da ofensiva neoliberal no mundo não deixa dúvidas. O seu grau de abrangência é condicionado pelo estágio das lutas de classes e das possibilidades concretas dispostas a partir das necessidades de acumulação capitalista. As contradições dessa forma de sociabilidade só poderiam ser resolvidas na sua própria imanência, no ataque à sua lógica fundamental. Ou seja, como veremos a seguir, é necessária uma nova forma de organização do trabalho e da produção da vida para uma solução efetiva, não sendo suficiente a administração política das contradições do capital.

Isso não significa, entretanto, o abandono das mediações políticas e das possibilidades de atuação dos trabalhadores por meio do aparelho estatal, como as diferentes formas de participação desenvolvidas nos anos recentes. Mas significa uma reorientação do caráter dessa forma de atuação, articulada a uma ação simultânea em outras esferas sociais.

O que se discutiu até aqui foi o problema de fixar determinada forma de organização, gestão ou atuação política como sendo universal, com capacidade de se desenvolver gradualmente até a superação do capital, independente das condições concretas e particulares. A nossa pesquisa aponta que o primeiro passo necessário para pensar e construir formas concretas de uma atuação emancipatória é compreender o caráter estra- 
nhado da produção capitalista que se cristaliza na forma do valor, o qual será brevemente apresentado agora.

\section{Valor, estranhamento e gestão estatal da força de trabalho}

A reprodução e valorização do capital se dão através de uma autonomização das forças sociais na esfera da produção e reprodução da vida material, que toma a aparência de um "poder não humano" (MARX, 2004 , p. 146) e que domina a todos, inclusive os capitalistas. Essa relação social, puramente humana e social, é o capital, "[...] trabalho morto, que, como um vampiro, vive apenas da sucção de trabalho vivo, e vive tanto mais quanto mais trabalho vivo suga" (MARX, 2013c, p. 307). Na sociedade capitalista, a produção material se torna meio para produção de valor.

Dessa forma, o processo de trabalho se torna processo de valorização. Isso é consequência à distinção entre trabalho útil e trabalho humano abstrato, sendo que o dispêndio deste último é o que cristaliza valor. O tempo de trabalho socialmente necessário para a produção de um valor de uso é o que determina a grandeza de seu valor. A forma mercadoria é a forma da unidade de valor de uso e valor de troca, sendo que "o valor de uma mercadoria está para o valor de qualquer outra mercadoria assim como o tempo de trabalho necessário para a produção de uma está para o tempo de trabalho necessário para a produção de outra" (MARX, 2013c, p. 117). Assim, na sociedade da produção de mercadorias plenamente desenvolvida, "[...] o tempo de trabalho socialmente necessário à sua produção se impõe com a força de uma lei natural reguladora, assim como a lei da gravidade se impõe quando uma casa desaba sobre a cabeça de alguém" (MARX, 2013c, p. 150). Esse fato tem consequências deletérias à sociabilidade armada sobre esse modo produção porque:

O tempo de trabalho como medida da riqueza põe a própria riqueza como riqueza fundada sobre pobreza e o tempo disponível como tempo existente apenas na e por meio da oposição ao tempo de trabalho excedente, ou significa pôr todo o tempo do indivíduo como tempo de trabalho, e daí a degradação do indivíduo. Por isso, a maquinaria mais desenvolvida força o trabalhador a trabalhar agora mais tempo que o fazia o selvagem ou que ele próprio com suas ferramentas mais simples e rudimentares. (MARX, 2013c, p. 591 grifos nossos).

Nesse modo de produção, a tecnologia não liberta o ser humano do trabalho; pelo contrário, ao transformá-lo em mero trabalhador, a divisão do trabalho capitalista "[...] torna supérfluo o próprio trabalhador", e uma "[...] população trabalhadora excedente é um produto necessário e [...] condição de existência do modo de produção capitalista [...]" (MARX, 
2013c, p. 557; p. 704). A contradição entre trabalho excedente e população excedente conforma o núcleo das mazelas sociais do capitalismo.

O próprio capital é a contradição em processo, [pelo fato] de que procura reduzir o tempo de trabalho a um mínimo, ao mesmo tempo que, por outro lado, põe o tempo de trabalho como única medida e fonte da riqueza. Por essa razão, ele diminui o tempo de trabalho na forma do trabalho necessário para aumentá-lo na forma do supérfluo; por isso, põe em medida crescente o trabalho supérfluo como condição - questão de vida e morte - do necessário. Por um lado, portanto, ele traz à vida todas as forças da ciência e da natureza, bem como da combinação social e do intercâmbio social, para tornar a criação da riqueza (relativamente) independente do tempo de trabalho nela empregado. Por outro lado, ele quer medir essas gigantescas forças sociais assim criadas pelo tempo de trabalho e encerrá-las nos limites requeridos para conservar o valor já criado como valor. As forças produtivas e as relações sociais - ambos aspectos diferentes do desenvolvimento do indivíduo social - aparecem somente como meios para o capital, e para ele são exclusivamente meios para poder produzir a partir de seu fundamento acanhado. (MARX, 2011b, p. 589).

Diferente da compreensão do mundo antigo, no que diz respeito ao atendimento das carências e necessidades como finalidade da produção, Marx (2011b, p. 389; p. 400 - grifos nossos) argumenta que, no mundo moderno, "[...] a produção aparece como finalidade do ser humano e a riqueza, como finalidade da produção". Essa "exteriorização total do conteúdo humano aparece como completo esvaziamento; essa objetivação universal, como estranhamento total, e a desintegração de todas as finalidades unilaterais determinadas, como sacrifício do fim em si mesmo a um fim totalmente exterior".

O modo de produção capitalista produz uma riqueza totalmente estranhada e compulsoriamente crescente, que subordina o trabalho vivo e amplia necessariamente o contingente de trabalhadores supérfluos, sujeitando o tempo livre gerado pelo desenvolvimento das forças produtivas ao fundamento miserável da riqueza na forma abstrata do valor.

Por essas razões, dadas as consequências para a própria reprodução do capital, o Estado, por meio da força policial, inicialmente e em seguida (e sempre) junto à legislação trabalhista e das reformas sociais, é rearticulado para garantir a acumulação capitalista. Esse processo conforma uma contradição na medida em que essas reformas sociais e trabalhistas são necessárias à própria sustentabilidade das sociedades capitalistas, mas só são tornadas possíveis a partir da luta organizada dos trabalhadores. Entretanto, não há aqui uma relação absoluta e abstrata que tornaria as reformas sociais um epifenômeno do desenvolvimento capitalista. As diferentes reformas, alcances, progressos e regressões ao longo dos últimos dois séculos nos países capitalistas demostram uma variedade de formas e 


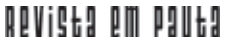

\} VALOR, ESTRANHAMENTO E LUTAS DE CLASSES - REZENDE, T. D. H. \}

DOI: $10.12957 /$ REP.2016.27840

conteúdos que são condicionados pela articulação entre as determinações mais gerais do capital e a particularidade histórico-concreta de cada país.

O que é concreto é a necessidade, desde a acumulação primitiva, que o Estado capitalista tem de uma ação econômica e social, intervindo diretamente no centro do funcionamento do capitalismo. De acordo com Brunhoff (1985), fundamental para a compreensão dessa intervenção é elucidar o papel da gestão estatal da força de trabalho. Conforme destaca a autora, a ação estatal, por meio da violência e da coação, condicionou a força de trabalho na fase de acumulação capitalista ao hábito necessário para a exploração especificamente capitalista dessa força, para então limitar a jornada de trabalho aos limites do exaurimento da força de trabalho logo depois. Isso ocorre porque a força de trabalho é uma mercadoria particular, cuja peculiaridade única de gerar valor também demanda uma tutela peculiar pela ação do Estado.

O excedente de trabalhadores em relação aos postos de trabalho e o exército industrial de reserva são fundamentais para a pressão salarial sobre os trabalhadores. Contudo, há consequências sociais contrárias à estabilidade das relações sociais, manifestas especialmente quando da luta organizada dos trabalhadores. É aí que a gestão estatal da força de trabalho intervém, para assegurar "[...] a reprodução da força de trabalho, dentro dos limites da manutenção de uma insegurança fundamental do emprego e através de formas que garantam a manutenção da disciplina no trabalho" (BRUNHOFF, 1985, p. 8). Além disso, "mesmo quando as modalidades se transformam, da assistência ao seguro ou ao Seguro Social, a forma da gestão estatal deve remeter à imposição capitalista do trabalho assalariado" (BRUNHOFF, 1985, p. 34).

O controle social exercido pela gestão estatal da força de trabalho não altera o fato de que o modo de produção capitalista produz uma riqueza totalmente estranhada e compulsoriamente crescente, subordinando o tempo livre gerado pelo desenvolvimento das forças produtivas ao fundamento miserável da riqueza na forma abstrata do valor. Pelo contrário, pretende assegurar as condições sociais para a reprodução da mercadoria especial e fundamental para a geração de valor, a força de trabalho.

A gestão estatal da força de trabalho age reafirmando a imposição do trabalho assalariado; entretanto, adequa a lógica do valor abstrato ao solo concreto e particular da reprodução do capital. As forças produtivas e as relações sociais subordinadas a uma finalidade exterior e às necessidades humanas fazem com que o capital seja caracterizado pela ausência de um controle social. A finalidade de cada produtor privado e individual é a riqueza abstrata, o valor, sendo indiferente a eles a utilidade e finalidade do que produzem. Pela troca de equivalentes, os produtores isolados tendem a produzir o máximo para obter a maior fração possível da riqueza social, daí o impulso à produção sempre crescente. Os produtores privados buscam sempre obter o máximo da riqueza social disponível na troca de 
equivalentes, sob pena de empobrecerem, já que a riqueza é sempre crescente. Daí a existência das formas políticas e de modos diferenciados de atuação estatal para a resolução das consequências sociais e humanas, enraizadas na própria esfera da produção.

O entendimento político mencionado no tópico anterior trata de buscar soluções na esfera da distribuição e redistribuição da riqueza social, gerada de modo a tentar solucionar os problemas advindos da acumulação capitalista. Como não é possível aos capitalistas buscar diretamente uma finalidade humana na sua produção, já que o lucro máximo é objetivo a ser perseguido sob pena de deixarem de ser capitalistas, é necessário que algo exterior, o Estado, atue como freio racional à irracionalidade da produção capitalista. A forma política que toma essa atuação é mediada pela particularidade histórica de cada lugar e pela intensidade das lutas de classes. Se, por um lado, o Estado atua para sustentar as relações capitalistas, sendo forma de dominação burguesa em geral, por outro lado ele permite ser colocado, por meio do atendimento das demandas dos trabalhadores, no horizonte tático dos trabalhadores, como veremos no tópico a seguir.

\section{Pluralidade dos estranhamentos e crítica ontológica}

O tempo de trabalho socialmente necessário como medida do valor, a forma de riqueza capitalista, torna o tempo de trabalho excedente fundamento da produção e, consequentemente, condição das relações e nexos entre os indivíduos sociais. Assim, a emancipação ocorre quando "o trabalho excedente da massa deixa de ser condição para o desenvolvimento da riqueza geral e [...] desmorona a produção baseada no valor de troca" (MARX, 2011b, p. 588). Ou seja, quando são recuperadas as forças produtivas e sociais estranhadas o conteúdo humano é perdido para os sujeitos que criam riqueza. Os indivíduos deixam a condição de meros trabaIhadores e se colocam "[...] ao lado do processo de produção, em lugar de ser seu agente principal" (MARX, 2011b, p. 588), numa transformação em que:

[...] o que aparece como a grande coluna de sustentação da produção e da riqueza não é nem o trabalho imediato que o próprio ser humano executa nem o tempo que ele trabalha, mas a apropriação de sua própria força produtiva geral, sua compreensão e seu domínio da natureza por sua existência como corpo social - em suma, o desenvolvimento do indivíduo social. (MARX, 2011b, p. 588).

Desse modo, a emancipação das barreiras limitadas e estreitas do capitalismo se liga fundamentalmente ao tempo livre, ao livre desenvolvimento das individualidades e ao uso pelos sujeitos das forças sociais, não mais estranhadas, "para a redução do trabalho necessário da sociedade 


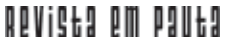

\} VALOR, ESTRANHAMENTO E LUTAS DE CLASSES - REZENDE, T. D. H. \}

DOI: $10.12957 /$ REP.2016.27840

como um todo a um mínimo, que corresponde então à formação artística, científica etc. dos indivíduos por meio do tempo liberado e dos meios criados para todos eles" (MARX, 2011b, p. 588).

Há uma retomada do controle social diretamente na esfera da produção. Essa constatação torna desafiador pensar em como as reformas sociais podem intervir nesse sentido, afinal, situadas dentro da lógica reprodutiva da sociedade capitalista e na esfera da distribuição, sua intervenção no modo de produção é limitada. Em Marx (2013a, p. 87), a preocupação com a desigualdade é secundária, e ele delega a "[...] tentativa de conciliar o inconciliável" a Stuart Mill. O desenvolvimento livre das individualidades e do controle consciente dos produtores livremente associados sobre sua produção e riqueza são os fundamentos da emancipação proposta por essa crítica radical ao capitalismo. Daí que a legislação fabril não é celebrada por Marx (2013a, p. 560) por atacar a desigualdade social, mas por usurpar a autoridade paterna ao proteger crianças e adolescentes, aprofundando o "[...] novo fundamento para uma forma superior da família e da relação entre os sexos". Além disso, também por contrapor-se ao caráter estranhado da produção ao ser a "primeira reação consciente e planejada da sociedade à configuração natural-espontânea de seu processo de produção" (MARX, 2013a, p. 551).

O estranhamento se retroalimenta na esfera da reprodução, onde a classe trabalhadora, "[...] por educação, tradição e hábito, reconhece as exigências desse modo de produção como leis naturais e evidentes por si mesmas" (MARX, 2013c, p. 808). Nesse sentido, as reformas sociais, o aparato estatal e a própria burocracia se tornam elementos importantes na afirmação desse modo de produção, seja para a repressão policial, seja para a conciliação dos antagonismos de classes. Nessa esfera, onde se desenvolvem as formas políticas particulares, abre-se o espaço para que a atuação dos trabalhadores se contraponha ao próprio capital, como também a outras formas de estranhamento.

O estranhamento fundamental do capital se articula a formas de estranhamento particulares, como as que aparecem nas relações de raça, gênero, sexo, nação, religião etc. Assim, na forma como se articulam as lutas sociais e as reformas sociais é necessário reter o "[...] modo pluralista de ser dos estranhamentos" (LUKÁCS, 2013, p. 607-608), pois há na sociedade "[...] pessoas que combatem influências estranhadoras num complexo do seu ser, enquanto aceitam outros complexos sem oferecer resistência".

Lukács (2013) usa como exemplo os trabalhadores que militam contra os capitalistas e causam um estranhamento tirânico a suas mulheres e crianças. Os estranhamentos na vida cotidiana são plurais e múltiplos, já "[...] que concepções falsas, preconceitos, interpretações equivocadas da realidade etc. podem persistir por um período bem mais longo na vida cotidiana que no próprio trabalho" (LUKÁCS, 2013, p. 442). Comum a 


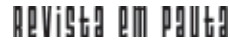

\} VALOR, ESTRANHAMENTO E LUTAS DE CLASSES - REZENDE, T. D. H. \}

DOI: $10.12957 /$ REP.2016.27840

todas as formas de estranhamento está o fato de interditarem uma consciência que eleve o sujeito da sua particularidade e perceba suas condições, privilégios e/ou desvantagens no interior de diferentes formas de estranhamento e, assim, possa combatê-los. Isto porque, "quanto mais particular um homem permanece, tanto mais impotente ele fica ao ser exposto a influências de estranhamento" (LUKÁCS, 2013, p. 607), e "o estranhamento é um dos fenômenos sociais que mais decididamente está centrado no indivíduo" (LUKÁCS, 2013, p. 585).

Nesse sentido, as diferentes lutas contra as discriminações, preconceitos, violência e opressões têm que estar necessariamente articuladas a uma luta anticapitalista. Desse modo, a utilização dos mecanismos e da burocracia estatal no combate às diferentes formas de opressão é um espaço concreto de atuação tática dos trabalhadores, rearticulando o aparato de dominação. A legislação social, a educação pública, a pesquisa científica e outros modos de utilização do aparelho estatal são formas de ação que podem atuar efetivamente no estabelecimento de condições objetivas e subjetivas para a emancipação humana.

O estabelecimento de uma estratégia para além do capital depende de uma crítica do ser do capital, à sua lógica imanente. Dessa maneira, tem-se que retomar a crítica ontológica ao capital e às formas de sociabilidade erguidas sobre esse modo de produção. Duayer (2011) afirma que crítica de fato é crítica ontológica, pois práticas emancipatórias de-pendem da apreensão das legalidades objetivas do mundo social. Ademais,

[...] a crítica ontológica da economia política, ao contrário de reduzir ou unilateralizar, induz e promove a universalização, estendendo o âmbito da análise desde a raiz ao todo da mundaneidade, natural e social, incorporando toda gama de objetos e relações. (CHASIN, 2009, p. 77).

Trata-se, portanto, de ir às raízes do ser social e desvelar as diferentes formas de estranhamento nos diferentes complexos desse ser, criticando todas as crenças e concepções que sustentam as práticas sociais e reprodutivas das relações limitadas dessa sociedade. A mera crítica nada transforma, mas como a "[...] prática humano-social é prática teleológica, intencional, finalística e, por isso, depende crucialmente de uma significação do mundo mais ou menos unitária e coerente" (DUAYER, 2011, p. 92), a crítica ontológica é fundamental para as práticas emancipatórias. Essa crítica "[...] ascende à decifração da mundaneidade imperfeita em sua realidade, para esclarecê-la, compreendendo sua gênese e necessidade, ou seja, para capturá-la em seu significado próprio [...]" (CHASIN, 2009, p. 74 - grifo no original). Trata-se da "[...] investigação do ente autoposto em sua imanência, seja esse uma formação real ou ideal [...]" (CHASIN, 2009, p. 74), de modo a reproduzir idealmente a lógica dos objetos analisados a partir deles mesmos, de seus nexos constitutivos, desvendando sua gênese e necessidade próprias. 


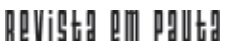

\} VALOR, ESTRANHAMENTO E LUTAS DE CLASSES - REZENDE, T. D. H. \}

DOI: $10.12957 /$ REP.2016.27840

A crítica ontológica volta-se à objetividade, à materialidade e aos diferentes modos de entificação dos complexos sociais na realidade concreta. Ela possibilita aos sujeitos interessados a real captação do caráter, dos limites e das possibilidades dos instrumentos e caminhos para as lutas sociais, sejam reformas sociais ou outras formas de organização e gestão da vida social que perspectivam uma sociabilidade para além do capital. Isso porque "tão só uma ininterrupta e vigilante crítica ontológica de tudo o que é reconhecido como fato ou conexão, como processo ou lei, é que pode reconstituir no pensamento a verdadeira inteligibilidade dos fenômenos" (LUKÁCS, 2012, p. 306).

Essa inteligibilidade é essencial para uma ação social voltada à transformação efetiva da realidade. Assim, a ação político-social tem sua validação nos resultados concretos e na particularidade em que se efetiva, não a partir de avaliação formal ou da vinculação ideal a determinada corrente política ou projeto político abstrato e arbitrário. Nesse sentido, para uma estratégia emancipatória, a potencialidade e efetividade das reformas sociais como meios de lutas podem ser esclarecidas pela exaustiva análise de realidade, já que "[...] a potência das mediações política e burocrática está submetida às circunstâncias históricas particulares" (PAÇO-CUNHA, 2016, p. 25). A crítica ontológica interdita o caminho que leva ao taticismo e à submissão da organização e da práxis emancipatória a instrumentos, aparelhos e formas políticas pré-definidas ou autonomizadas a partir do solo concreto de sua instauração. Portanto, as análises aqui apresentadas apontam que as lutas dos trabalhadores devem comportar uma simultaneidade de ações em todas as esferas abertas à sua atuação emancipatória.

\section{Considerações finais}

A crítica ontológica da economia política marxiana apontou o caráter central do estranhamento como fundamento da produção mercantil baseada no tempo de trabalho excedente como medida da riqueza. Além disso, pela importância da particularidade histórica de cada lugar, evidencia-se a necessidade de se enfatizar o combate a todas as formas de estranhamento enquanto prioridade de um projeto societário que pretenda superar a ordem capitalista e todas as formas de opressões herdadas e reconfiguradas pelo capital. Isso não só através do combate negativo dos estranhamentos existentes já identificados, mas também no desvelamento das formas de estranhamento inconscientes. Afinal, "o modo pluralista de ser dos estranhamentos [...] equivale a complexos dinâmicos do estranhamento qualitativamente distintos e às suas tentativas conscientes, subjetivas de superação" (LUKÁCS, 2013, p. 607). Para tanto, é fundamental retomar a crítica ao ser dos estranhamentos, ou seja, retomar a crítica ontológica por ser 


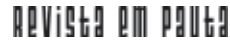

\} VALOR, ESTRANHAMENTO E LUTAS DE CLASSES - REZENDE, T. D. H. \}

DOI: $10.12957 /$ REP.2016.27840

aquela que lida "[...] com o pensamento no complexo real onde se manifesta como força específica de um ser peculiar nos atos pelos quais este se confirma" (CHASIN, 2009, p. 102).

O caráter limitado da resolução das mazelas sociais por meio das reformas sociais é imanente às diferentes formas políticas erigidas sobre o modo de produção capitalista. Além disso, é temeroso supor que um desenvolvimento de uma forma política baseada nas contradições capitalistas fundamentais poderia levar gradualmente à superação do próprio capitalismo. Assim, não existe uma determinada forma política como meio universal de transformação social descolada de sua base material, desconsiderando as diferentes variáveis locais, das determinações econômicas em última instância às múltiplas formas de instituições, costumes e tradições. No entanto, o espaço aberto pela necessária gestão estatal da força de trabalho é contraditório.

As reformas sociais, não sendo meio absoluto, podem entrar no conjunto de meios possíveis a serem utilizados pelos trabalhadores simultaneamente e articulados a outros na sua estratégia emancipatória, especialmente com o suporte de uma crítica ontológica que esclareça cada vez mais as possibilidades concretas de cada forma de atuação. A ação estatal se orienta pela reafirmação dos requisitos da produção de valor; entretanto, contraditoriamente, abre o espaço para uma atuação que permite que os trabalhadores tenham melhores condições de vida e tempo para organização política e social, além de solucionar as mazelas urgentes que afligem grande parte da população sob o império do capital.

Essa atuação, tendo em vista os mecanismos de participação e intervenção democrático-popular por meio do Estado, não elimina a necessidade das lutas organizadas na esfera produtiva, além da necessária alteração do estatuto da propriedade privada e da reorganização social da produção. Ela se soma a uma simultaneidade de ações dos trabalhadores, nas quais todos os espaços forçosamente cedidos pelo capital ao trabalho devem ser tensionados numa perspectiva emancipatória que não sucumba ao ardil do politicismo ou à impotência do indiferentismo político. 


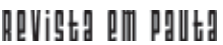

\} VALOR, ESTRANHAMENTO E LUTAS DE CLASSES - REZENDE, T. D. H. \}

DOI: $10.12957 /$ REP.2016.27840

\section{Referências}

BORÓN, A. Hegemonía e imperialismo en el sistema internacional. In: BORGIANNI, E.; MONTAÑO, C. (Org.). Coyuntura actual, latinoamericana y mundial: tendências y movimientos. São Paulo: Cortez, 2009.

BRUNHOFF, S. de. Estado e capital: uma analise da política econômica. Rio de Janeiro: Forense Universitária, 1985.

CHASIN, J. Hasta cuándo? A propósito das eleições de novembro. Nova Escrita/Ensaio, São Paulo, 1982.

. Marx: estatuto ontológico e resolução metodológica. São Paulo: Boitempo, 2009.

CHESNAIS, F. Mundialización: el capital financiero en el comando. In: BORGIANNI, E.; MONTAÑO, C. (Org.). Coyuntura actual, latinoamericana y mundial: tendências y movimientos. São Paulo: Cortez, 2009.

COUTINHO, C. Contra a corrente: ensaios sobre democracia e socialismo. São Paulo: Cortez, 2000.

DUAYER, M. Mercadoria e trabalho estranhado: Marx e a crítica do trabalho no capitalismo. Margem Esquerda, São Paulo, v. 17, nov. 2011.

DUAYER, M.; MEDEIROS, J. L. G. Marx, estranhamento e emancipação: o caráter subordinado da categoria da exploração na análise marxiana da sociedade do capital. Revista de Economia, Curitiba, v. 34, 2008.

FMI. INTERNATIONAL MONETARY FUND. Causes and consequences of income inequality: a global perspective. Washington: IMF Policy Paper, 2015.

GOUGH, I. Economía política del Estado del bienestar. Madrid: H. Blume Ediciones, 1978.

HARVEY, D. The new imperialism. Nova York: Oxford University Press, 2003.

IGREJA CATÓLICA. Papa Francisco. Carta encíclica Laudato Si': sobre o cuidado da casa comum. Roma: Libreria Editrice Vaticana, 2015.

KRUGMAN, P. End this depression now! Nova York/Londres: W. W. Norton \& Company, 2012.

. Why we're in a new gilded age. The New York Review of Books, 2014. Disponível em: <http://www.nybooks.com/articles/archives/2014/ may/08/thomas-piketty-new-gilded-age/>. Acesso em: 29 dez. 2015.

LUKÁCS, G. Para uma ontologia do ser social I. São Paulo: Boitempo, 2012. . Para uma ontologia do ser social II. São Paulo: Boitempo, 2013. 
MARX, K. On the hague congress. Collected Works, Londres: Lawrence \& Wishart, v. XXIII, 1988a.

. Political indifferentism. Collected Works, Londres: Lawrence \& Wishart, v. XXIII, 1988b.

. Manuscritos econômico-filosóficos. São Paulo: Boitempo, 2004.

. Glosas críticas ao artigo "O Rei da Prússia e a reforma social'. De um prussiano". In: Lutas de classes na Alemanha. São Paulo: Boitempo, 2010.

. A guerra civil na França. São Paulo: Boitempo, 2011 a.

. Grundrisse. São Paulo: Boitempo, 2011 b.

. Carta à redação da Otechestvenye Zapiski, 1877. In: MARX, K; ENGELS, F. Lutas de classes na Rússia. São Paulo: Boitempo, 2013a.

. A correspondência entre Vera Zasulich e Karl Marx. In: MARX, K; ENGELS, F. Lutas de classes na Rússia. São Paulo: Boitempo, 2013 b.

. O capital. Livro 1. São Paulo: Boitempo, 2013c.

NAVARRO, V. Neoliberalismo y Estado del bienestar. Barcelona: Ed. Ariel, 1998.

PAÇO-CUNHA, E. Movimento real da forma política em Marx: elementos para a crítica dos aparelhos repressivos como síntese do estado capitalista. In: MARX E O MARXISMO 2015: INSURREIÇÕES, PASSADO E PRESENTE, 9., 2015, Niterói. Anais... Niterói: Niep-Marx, 2015.

. Que fazer da burocracia de estado? Do indiferentismo às reciprocidades. Administração Pública e Gestão Social, v. 8, 2016.

PEREIRA, C. Proteção social no capitalismo: contribuições à crítica de matrizes teóricas e ideológicas conflitantes. Tese (Doutorado em Política Social) - Instituto de Ciências Humanas, UNB, Brasília, 2013.

PIKETTY, T. Capital in the twenty-first century. Cambridge: The Belknap Press of Harvard University Press, 2014.

Recebido em 30 de julho de 2016.

Aprovado para publicação em 22 de novembro de 2016.

DOI: $10.12957 /$ rep.2016.27840

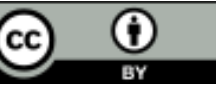

A Revista Em Pauta: Teoria Social e Realidade Contemporânea está licenciada com uma Licença Creative Commons Atribuição 4.0 Internacional. 